\title{
THE EFFECT OF THE VALSALVA MANEUVRE ON THE SYSTEMIC AND PULMONARY ARTERIAL PRESSURE IN MAN
}

\author{
BY
}

\author{
G. DE J. LEE, M. B. MATTHEWS, AND E. P. SHARPEY-SCHAFER
}

From St. Thomas's Hospital

Received April 2, 1954

There is little information concerning reflex vasomotor activity in the pulmonary arterial system in man. Pulmonary arterial resistance is known to increase during anoxia (Motley et al., 1947; Doyle, et al., 1952) and animal experiments suggest that this is a local effect on the vessels themselves (von Euler and Liljestrand, 1948; Duke, 1951). de Burgh Daly et al. (1932 and 1948) have produced pulmonary arterial constriction by electrical stimulation of the stellate ganglion and of the cervical and thoracic vago-sympathetic system of the perfused dog, but this effect is small in the intact animal (Daly, 1954).

Numerous afferent pathways exist from the lesser circulation, and the activity of some of these increases with a rise in pulmonary arterial pressure (Pearce and Whitteridge, 1951; Aviado et al., 1951). The efferent pathways which these nerves influence have not been traced anatomically, but Aviado et al. (1951) have demonstrated systemic vasodilatation resulting from increased perfusion pressure in the pulmonary artery of the dog.

In man, the Valsalva manœuvre produces characteristic changes in the systemic blood pressure, which are largely due to vasoconstriction (Knoll, 1894). Wilkins et al. (1948) showed that the rise in systemic blood pressure following the Valsalva manœuvre was abolished by thoracolumbar sympathectomy. Tetraethyl ammonium chloride produces a similar effect (Greene, et al., 1950). Sharpey-Schafer (1953) has shown that the increased arterial pressure following the Valsalva manœuvre was associated with a decrease in forearm blood flow, except in the sympathectomized limb.

In the present communication the Valsalva manœuvre has been used to compare the vasomotor responses of the systemic and pulmonary arterial systems simultaneously.

\section{METHODS}

Ten male patients admitted to hospital with a variety of conditions, who showed a normal blood pressure response to the Valsalva manœuvre, were studied (Valsalva, 1707).

All pressure measurements were made using Hansen capacitance manometers (Hansen, 1949) with reference point $10 \mathrm{~cm}$. anterior to the back of the recumbent subject. The brachial arterial pressure was obtained with an indwelling needle; the intra-thoracic pressure from a water-filled catheter in the œsophagus (Dornhorst and Leathart, 1952); pressures from right atrium, pulmonary artery, and "pulmonary capillary" (Hellems et al., 1949) were obtained using standard techniques. Each subject received $1 \mathrm{mg}$. atropine sulphate intravenously prior to the investigation to restrict pulse rate changes. The manometers recording intracardiac and intra-œsophageal pressure were used in conjunction with one another as a differential manometer. The electrical output from one manometer was opposed to that of the other and the resultant represented the 
differential pressure (net R.A., P.A., and P.C. pressures). Fig. 1 shows this differential system to be satisfactory. Both the direct and differential recording manometers were exposed to the same pressure changes from a common pressure bottle. The differential pressure between the two manometers was zero over a wide range of both negative and positive pressures. The differential system also behaved satisfactorily to rapid pressure fluctuations.

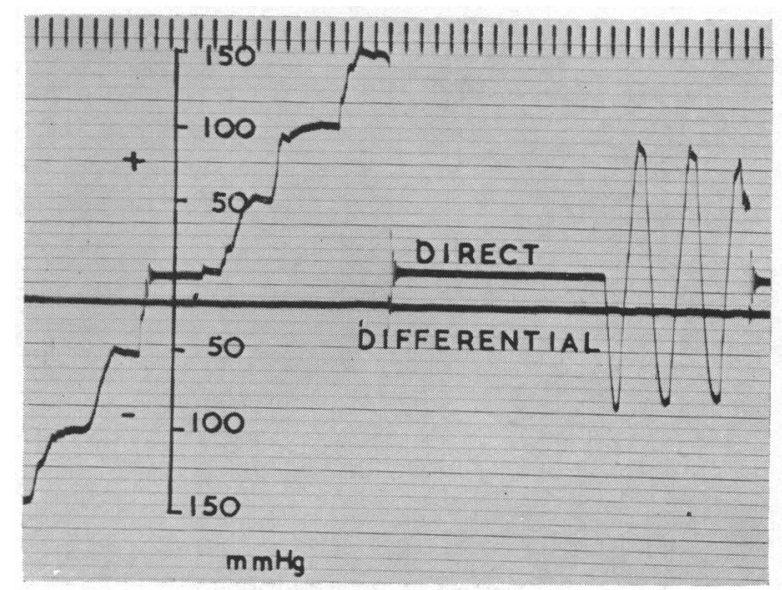

Fig. 1.-Simultaneous tracings from direct and differential manometers exposed to the same pressure change.

\section{RESULTS}

The Normal Response of the Systemic and Net Pulmonary Arterial Pressure to the Valsalva Manæuvre. All ten subjects showed similar responses to a varying degree.

The systemic blood pressure falls after an initial rise equivalent to the rise in intrathoracic pressure during the period of expiratory effort. Mean and pulse pressures fall as heart filling is

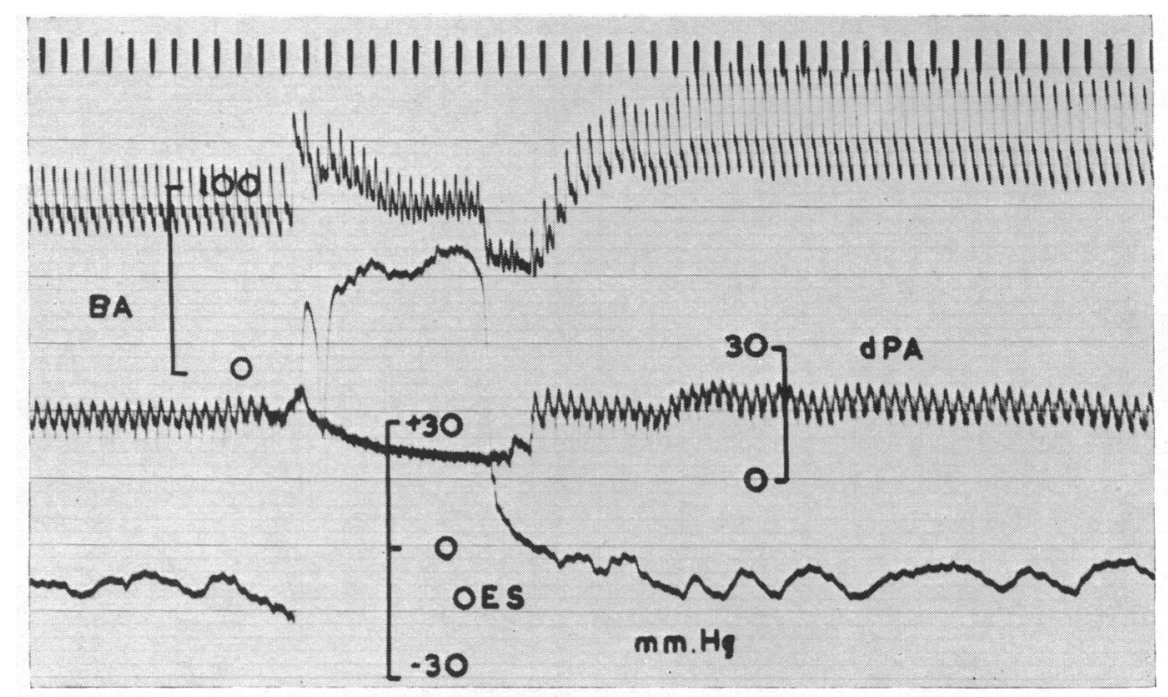

FIG. 2.-The effect of the Valsalva manœuvre on brachial and net pulmonary arterial pressures. Time in seconds. $\quad B A=$ brachial arterial pressure. $\mathrm{dPA}=$ net pulmonary arterial pressure. OES=inter-cesophageal pressure. Following the Valsalva there is a marked rise in brachial arterial pressures but little rise in pulmonary arterial pressure. 
impaired. With release of the Valsalva there is a very great rise in mean pressure, and some rise in pulse pressure. The usual accompanying bradycardia has been prevented by atropine. The net pulmonary arterial pressure also falls as heart filling is reduced by the raised intrathoracic pressure. With release of the blown pressure there is some rise of both mean and pulse pressure above the resting level, but this is much less than the overshoot in the brachial artery (Fig. 2).

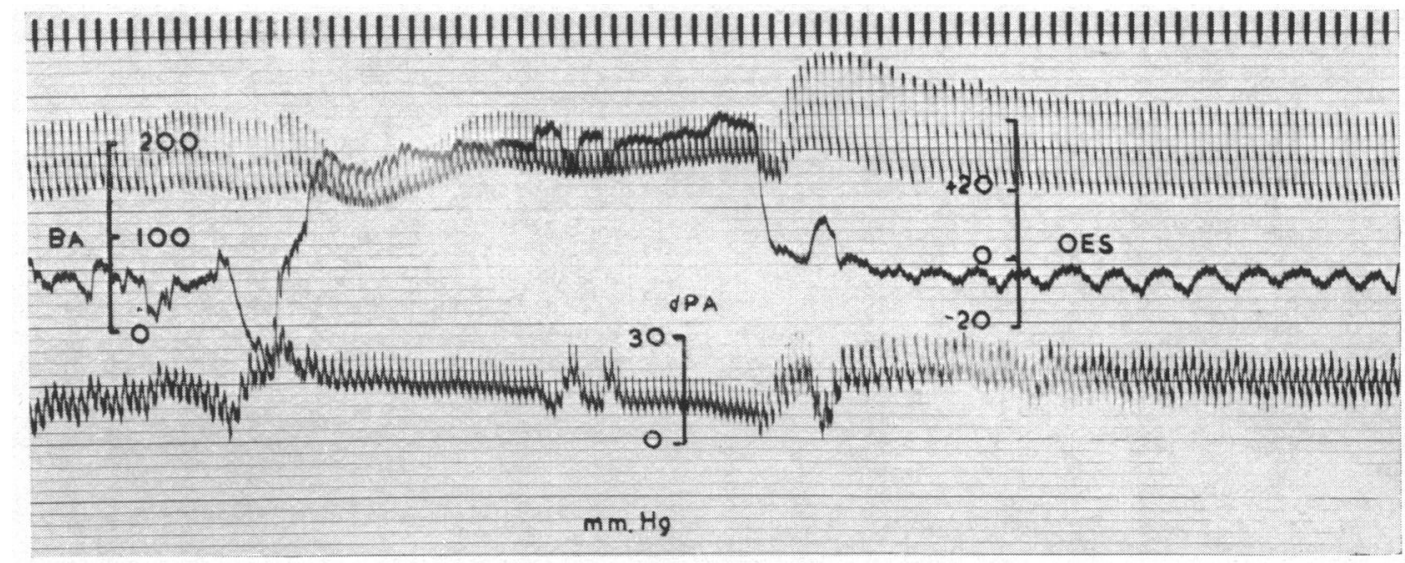

FIG. 3.-During the prolonged Valsalva manœuvre the brachial arterial pressure rises; no corresponding rise occurs in the net pulmonary arterial pressure.

When the Valsalva manœuvre is prolonged (Fig. 3) the mean systemic pressure shows the usual initial fall and then begins to rise. Waxing and waning of the blood pressure then occurs similar to the Traube waves seen in apnoa (Traube, 1865), but the changes in pulse pressure during the same period are small. The net pulmonary arterial pressure shows no such changes during the Valsalva: after the initial fall in mean and pulse pressure there is no subsequent rise in pressure, nor does any wave pattern develop. The two sharp falls and rises in net pulmonary arterial pressure during the Valsalva manœuvre are artefacts due to contraction waves in the œsophagus affecting the differential

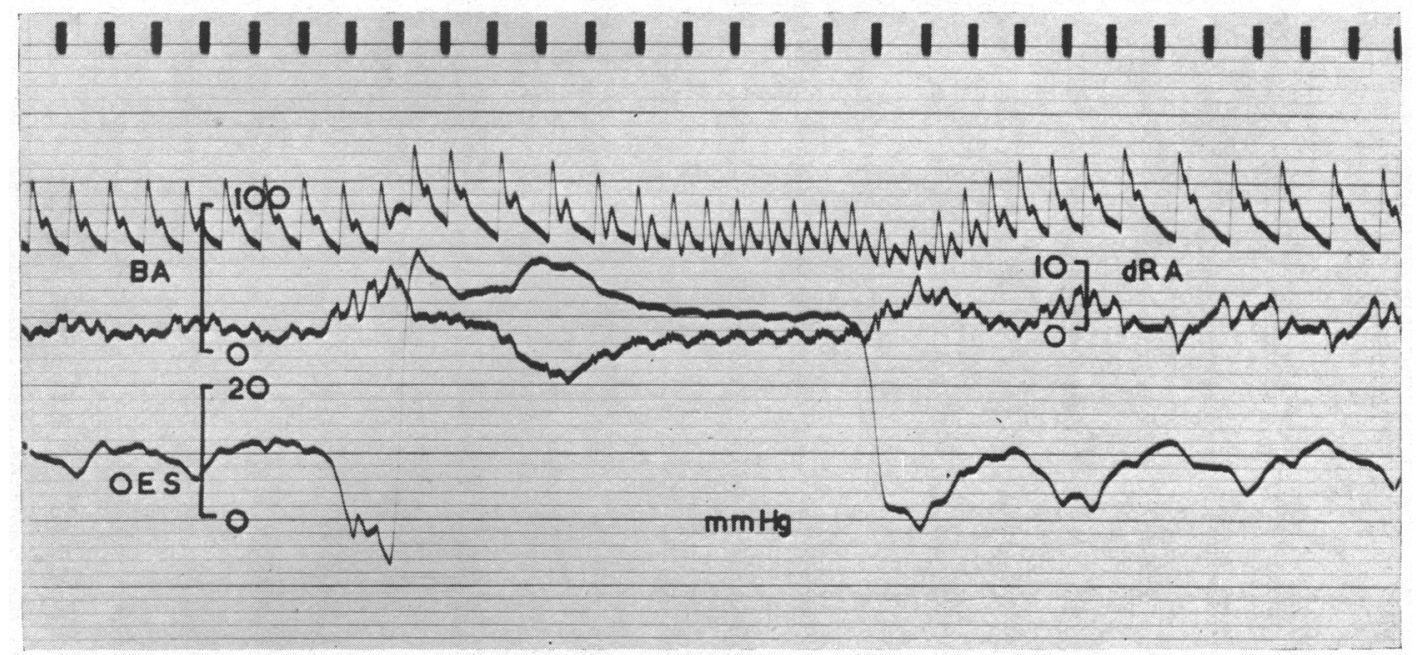

FIG. 4.-The effect of the Valsalva manœuvre on net right atrial pressure. $d R A=$ net right atrial pressure. $\mathbf{X}$ Both the brachial and net right atrial pressures rise following the Valsalva. 


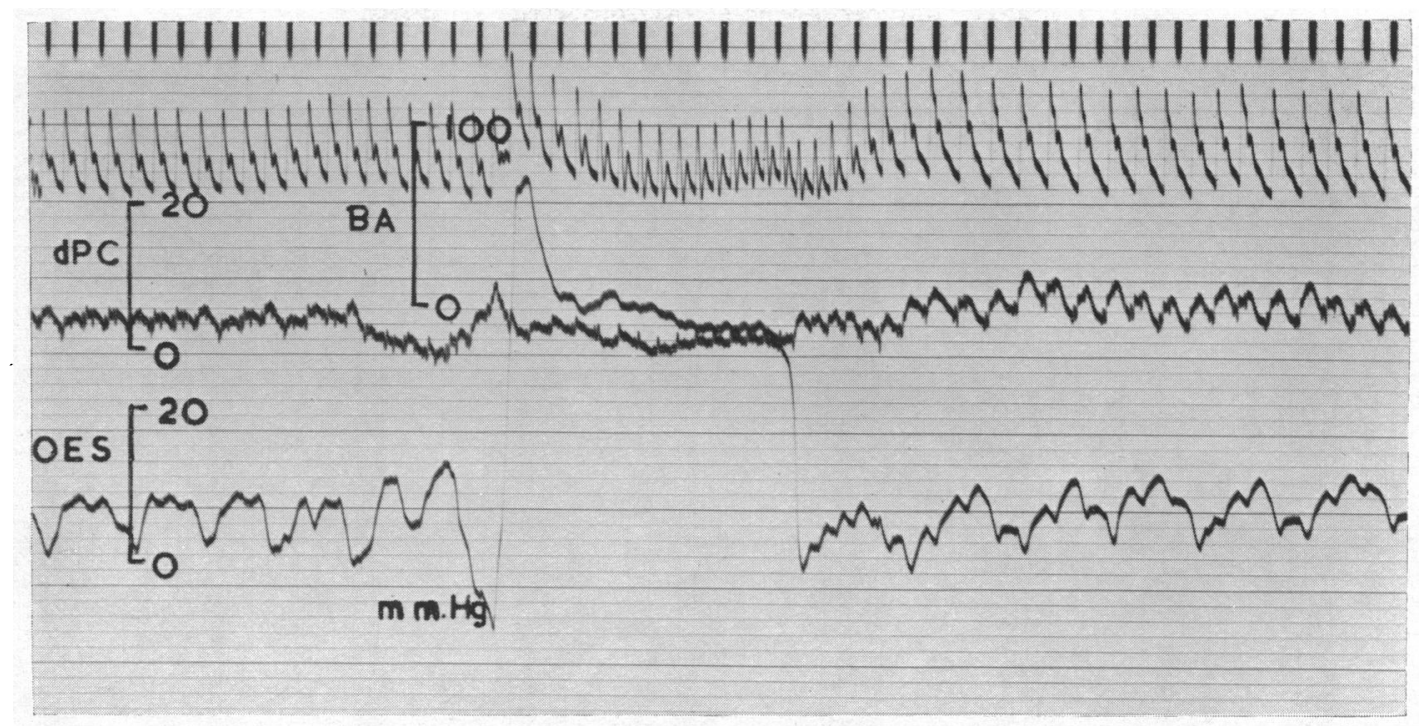

Fig. 5.-The effect of the Valsalva manœuvre on net pulmonary capillary pressure. dPC=net " pulmonary capillary" pressure. Both the brachial and net pulmonary capillary pressure rise following the Valsalva.

system. Similarly, following the Valsalva, a swallow wave in the œsophagus has superimposed a negative artefact upon the net pulmonary arterial pressure tracing.

Net Right Atrial and Net Pulmonary Capillary Pressures during the Valsalva Mancuvre. The net right atrial pressure rose following the release of the Valsalva, the rise being modified by the phase of respiration. However, if pressures are compared during similar phases of respiration a rise of $3 \mathrm{~mm}$. in expiration and $7 \mathrm{~mm}$. $\mathrm{Hg}$ on inspiration occurred following release of the blown pressure (Fig. 4).

The net pulmonary capillary pressure from the same subject as in Fig. 4 shows an almost identical rise following the Valsalva manœuvre. The rise occurs four to five pulse beats after release

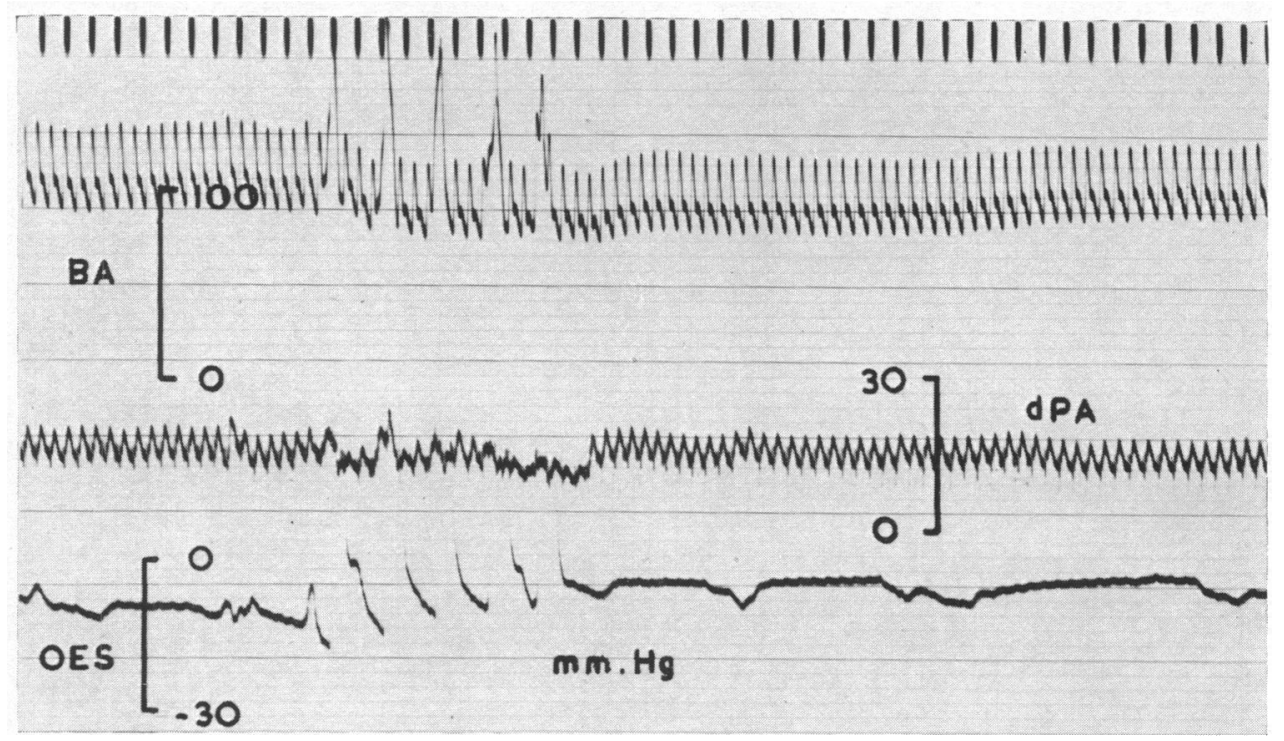

FIG. 6.-Following coughing there is a transient fall in brachial but not in net pulmonary arterial pressure. 
of the blown pressure. There is not the same degree of modification by respiration as was seen in the right atrium.

The Effect of Coughing on Systemic and Net Pulmonary Arterial Pressure. Following a few hearty coughs, the mean systemic blood pressure falls temporarily with little change in pulse pressure. No apparent change occurred in the net pulmonary arterial pressure (Fig. 6).

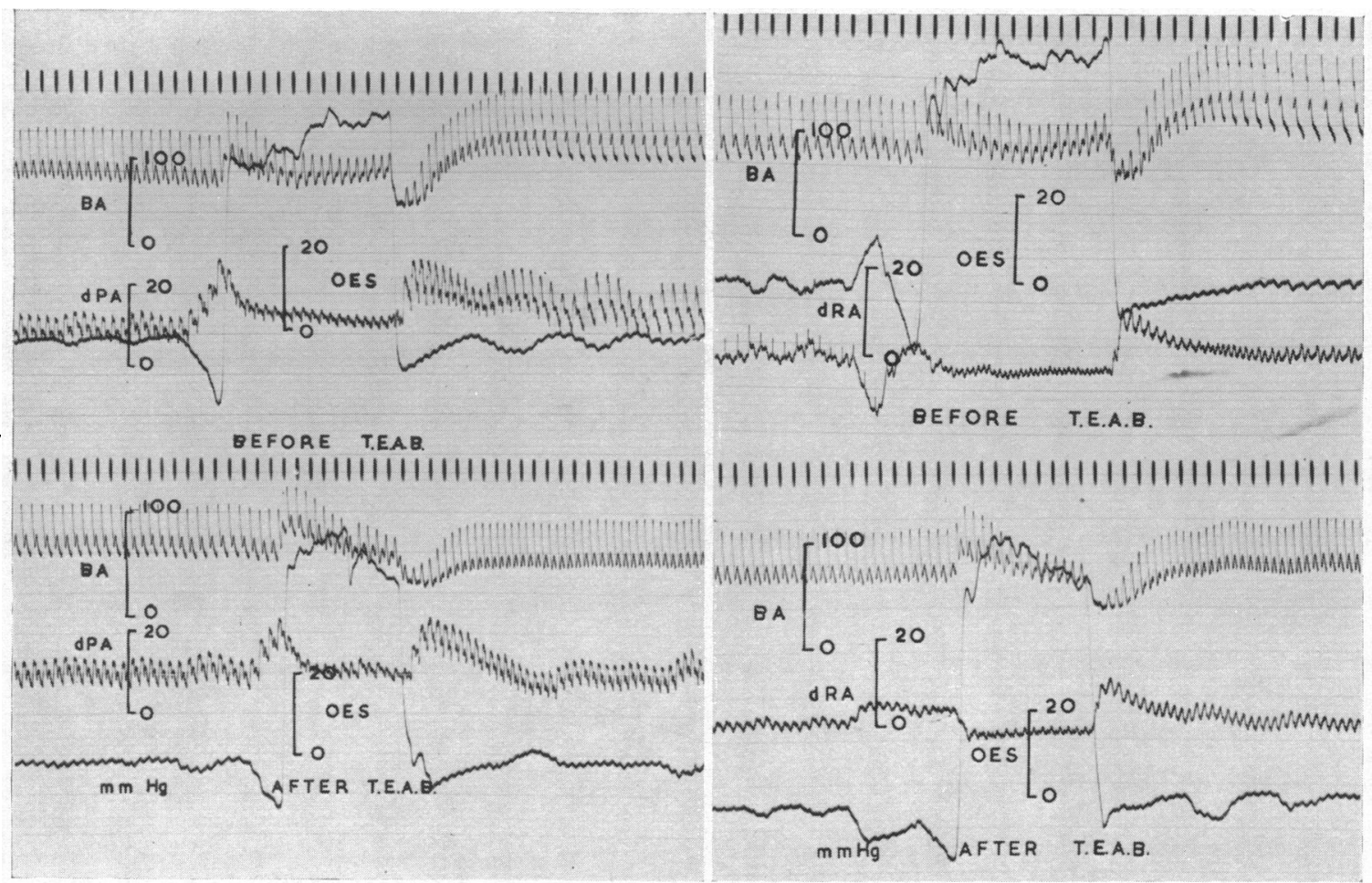

Fig. 7.-T.E.A.C. abolishes the rise in brachial arterial pressure following the Valsalva. It does not greatly influence the pulmonary arterial pressure rise.

FIG 8.-As Fig. 7. The net right atrial pressure rise is uninfluenced by T.E.A.C.

The Effect of Tetraethyl Ammonium Chloride. In three subjects an intravenous infusion of $0.3 \mathrm{mg}$. $/ \mathrm{kilo} /$ minute of tetraethyl ammonium chloride abolished the rise in systemic arterial pressure following the Valsalva manœuvre (Fig. 7 and 8).

The net right atrial and pulmonary arterial pressure rise was virtually unaffected.

\section{Discussion}

In the present investigation, the Valsalva manœuvre was followed by the usual rise in systemic blood pressure associated with vasoconstriction (Knoll, 1894). However, evidence was found that the simultaneous rise in net pulmonary arterial pressure was due to an increase in venous return, for the net right atrial pressure also showed a striking rise, in some instances of as much as $20 \mathrm{~mm}$. $\mathrm{Hg}$ following a particularly prolonged Valsalva manœuvre (Fig. 4). Almost identical changes occur in net pulmonary capillary pressure (Fig. 5). It is, therefore, reasonable to conclude that with the rapid increase in right ventricular filling pressure following the Valsalva, there is an associated rapid rise in stroke output which accounts for the rise in pulmonary arterial pressure. Perhaps of greater significance is the fact that no rise in pulmonary arterial pressure independent of pulmonary capillary pressure occurred. This strongly suggests that no pulmonary arteriolar constriction has taken place, and there is further evidence to the same effect when the pulmonary 
and brachial arterial pressure tracings obtained during the prolonged Valsalva manœuvre are compared. During this period, venous return is restricted and stroke output reduced; reflex vasoconstriction occurs in the systemic arterial system, indicated by a rise in mean pressure, and later Traube waves appear (Fig. 3). These indications of alteration in vasomotor tone do not occur in the pulmonary arterial pressure.

Sharpey-Schafer (1953) has shown that by inducing big pulse pressure transients in the systemic arterial system by coughing, reflex vasodilatation will occur, as indicated by a fall in systemic blood pressure and a rise in forearm blood flow. Coughing produced no similar change in net pulmonary arterial pressure (Fig. 6).

Greene and Bunnell (1950) showed a fall in net pulmonary arterial pressure in man following continuous intravenous infusions of tetraethyl ammonium chloride (T.E.A.C.) and, in their opinion, the accompanying fall in cardiac output did not fully account for the fall in pulmonary arterial pressure. They also showed that T.E.A.C. abolished the "overshoot" that they were able to demonstrate in the pulmonary arterial pressure, and on this evidence concluded that there was reflex pulmonary vasomotor activity. We cannot confirm this. In three cases sufficient T.E.A.C. to abolish the systemic arterial overshoot following the Valsalva produced negligible changes in the response of the net right atrial and pulmonary arterial pressures (Fig. 7 and 8). This was taken as further evidence against pulmonary arteriolar constriction.

It therefore appears that under the circumstances described, reflex vasomotor changes, if present, are much less in the pulmonary arterial than in the systemic system. These observations and conclusions are almost identical with those made by Hamilton et al., (1939) on unanæsthetized dogs.

\section{SUMMARY}

The brachial arterial, net right atrial, pulmonary arterial, and pulmonary capillary pressures were recorded simultaneously in ten subjects performing the Valsalva manœuvre. In three, the effects of tetraethyl ammonium chloride were studied.

There was a marked rise in systemic arterial pressure following the Valsalva, largely due to reflex vasconstriction. The rise in net pulmonary arterial pressure was accompanied by a similar rise in net right atrial and pulmonary capillary pressures. Only the systemic arterial pressure rise was abolished by T.E.A.C., the net pulmonary arterial pressure response being unaffected.

No evidence of reflex pulmonary arterial vasoconstriction could be demonstrated.

We are indebted to R. W. Halls and M. Vento for technical assistance and to the St. Thomas's Hospital Photographic Department for the reproductions.

\section{REFERENCES}

Aviado, D. M., Jr., Li, T. H., Kalow, W., Schmidt, C. F., Turnbull, G. L., Peskin, G. W., Hess, M. E., and Weiss, A. J. (1951). Amer J. Physiol., 165, 261.

Bunnell, I. L., Greene, D. G., and Kunz, W. W. (1951). J. Applied Physiol., 4, 345.

Daly, I. de B., and von Euler, V. (1932). Proc. Roy. Soc., B., 110, 92.

-, Duke, H., Hebb, C. O., and Weatherall, J. (1948). Quart. J. Exp. Physiol., 34, 285.

Daly, M. de B. (1954). Unpublished data.

Dornhorst, A. C., and Leathart, G. L. (1952). Lancet, 2, 109.

Doyle, J. T., Wilson, J. S., and Warren, J. V. (1952). Circulation, 5, 263.

Duke, H. N. (1951). Quart. J. Exp. Physiol., 36, 75.

Greene, D. G., and Bunnell, I. L. (1950). J. Clin. Invest., 29, 818.

Hamilton, W. F., Woodbury, R. A., and Vogt, E. (1939). Amer. J. Physiol., 125, 130.

Hansen, T. A. (1949). Acta Physiol. Scand., 19, Suppl. 68.

Hellems, H. K., Haynes, F. W., and Dexter, L. (1949). J. Applied Physiol., 2, 24.

Knoll, P. (1894). Arch. ges. Physiol., 57, 406.

Motley, H. L., Cournand, A., Werkö, L., Kimmelstein, A., and Dresdale, D. T. (1947). Amer. J. Physiol., $150,315$.

Pearce, J. W., and Whitteridge, D. (1951). Quart. J. Exp. Physiol., 36, 177.

Sharpey-Schafer, E. P. (1953). J. Physiol., 122, 351 .

Traube, L. (1865). Centralbl. med. Wissensch., 3, 881.

Valsalva, A. M. (1707). De Aure Humana. Traj. ad Rhenum [Utrecht] G. vande Water, p. 84.

von Euler, U. S., and Liljestrand, G. (1946). Acta Physiol. Scand., 12, 301.

Wilkins, R. W., Cuthbertson, J. W., and Smithwick, R. H. (1948). Surg. Gynaec. Obstet., $87,661$. 